\& Solomon M.A. (1986) Ferromagnetism of intraocular foreign body causes unilateral blindness after MR study. American Journal of Neuroradiology 7, 243-245.

5. Wesley R.E., Wahl J.W., Loden J.P. \& Henderson R.R. (1982) Management of wooden foreign bodies in the orbit. Southern Medical Journal 75, 924-926.

\section{The Patient's Charter: views of patients attending an inner-city accident and emergency department}

\section{SUMMARY}

We conducted a prospective study of patient's understanding of the Patient's Charter. Every patient attending the Accident and Emergency (A\&E) Department of St Bartholomew's Hospital over a 7-day period was questioned by an interviewer. Those not interviewed by this process were sent a postal questionnaire. A total of 584 patients attended during the study period, from whom 451 data sets were collected, a response rate of $77 \%$. Only 51 patients were aware of The Patient's Charter guarantee of 'immediate assessment'. When asked what they understood by 'immediate', $67 \%$ of respondents considered this to mean $15 \mathrm{~min}$ or longer. Fifty-four per cent of respondents felt that this assessment should be performed by a nurse. A follow-up study conducted over a 48-h period in January 1994 showed no significant difference in the responses to the same questions.

We conclude that the vast majority of patients in this study exhibited a very low level of awareness regarding the guarantees of The Patient's Charter.
We also note that their interpretation of the term 'initial assessment' is at variance with that expressed by the NHS Chief Executive in a widely circulated document. $^{1}$

\section{METHODS AND RESULTS}

We conducted an interview-based survey of all patients attending the A\&E Department of St Bartholomew's Hospital from 17 to 24 August 1992. This is an inner-city department serving a mixed commuter and residential population and 40000 new patients present per year.

A pilot study was performed in which patients were asked to complete a questionnaire handed to them by the reception clerk. A very poor completion rate $(10 \%)$ and misinterpretation of several questions led us to adopt an interview-based approach. Medical staff and volunteer medical students mounted a 24-h rota in an attempt to intercept every patient attending the department in the 7-day period. They asked standardized questions from a pre-printed questionnaire (patients not interviewed were sent a postal questionnaire).

A total of 584 patients were registered during the course of the study, of whom 404 were interviewed on their initial attendance $(69 \%)$. A further 47 responded to the postal questionnaire, giving a total of 451 data sets. The interviewers recorded 51 cases in which they were unable to conduct the interview because of communication difficulties, lack of cooperation or severity of illness. The completion rate among the 533 patients who were in a position to complete the questionnaire was $85 \%$.

There were variable rates of response for each of

\begin{tabular}{|c|c|c|c|}
\hline \multicolumn{2}{|l|}{ Question } & $\begin{array}{c}\text { No. of } \\
\text { patients }\end{array}$ & $\begin{array}{l}\text { Response } \\
\text { rate }(\%)\end{array}$ \\
\hline \multicolumn{2}{|c|}{$\begin{array}{l}\text { 1. Were you aware of your guarantee (a) Yes } \\
\text { of immediate assessment on }\end{array}$} & 51 & \multirow[t]{2}{*}{94} \\
\hline arrival in the A\&E department? & (b) No & 372 & \\
\hline \multirow{5}{*}{$\begin{array}{l}\text { 2. What period of time do you think } \\
\text { is appropriate for 'immediately'? }\end{array}$} & (a) Within 1 min & 39 & \multirow{5}{*}{90} \\
\hline & (b) Within 5 min & 93 & \\
\hline & (c) Within $15 \mathrm{~min}$ & 179 & \\
\hline & (d) Within $1 \mathrm{~h}$ & 87 & \\
\hline & (e) Longer & 7 & \\
\hline \multirow{4}{*}{$\begin{array}{l}\text { 3. Who do you think should perform } \\
\text { your initial assessment? }\end{array}$} & (a) Doctor & 155 & \multirow{4}{*}{91} \\
\hline & (b) Nurse & 221 & \\
\hline & (c) Receptionist & 32 & \\
\hline & (d) Other & 3 & \\
\hline
\end{tabular}

Table 1. Facsimile of the questionnaire 
the individual questions ranging from 90 to $94 \%$. The results and response rates to the individual questions are shown in Table 1.

Of people responding to the question relating to the content of The Patient's Charter, $88 \%$ were unaware of its guarantees. When asked to interpret the term 'initial assessment' $67 \%$ of responders felt that $15 \mathrm{~min}$ or longer would be appropriate and $62 \%$ felt that it should be performed by someone other than a doctor.

Our follow-up study performed in January 1994 over a 48-h period was conducted in exactly the same manner. Of 173 patients attending during this period, completed data sets were collected for 134 $(77 \%)$. Of these, $83 \%$ were unaware of the 'initial assessment' guarantee, $64 \%$ felt that it should be performed within $15 \mathrm{~min}$ or longer and $71 \%$ felt that it should be a nursing or non-medical task.

\section{DISCUSSION}

The Department of Health published The Patient's Charter amidst a blaze of publicity. Despite the Government's best efforts it appears that only $12-17 \%$ of patient's in our studies were aware of the standard that they should be seen and assessed immediately on arrival in an A\&E department. Moreover, when asked directly, approximately two-thirds felt that this term implied assessment within 15 min or longer. We imagine that this finding will be of interest to the NHS Management Executive who insist that 'immediate assessment' should be interpreted literally, with a maximum latitude of $5 \mathrm{~min}$. However, our findings show that the suggestion by the NHS Management Executive that this assessment should be performed by a nurse accords with patient expectations.

These results have important implications for those providing A\&E services. There have been several incidences around the country of A\&E departments being fined, or threatened with fines, by purchasing authorities for not achieving these charter standards. It is the patients who should decide what standards they expect from A\&E departments, rather than managers who claim to be acting on their behalf. The current Government obsession with achieving charter standards has obscured the more important aim of maintaining and improving standards of clinical care. It has caused hours of pointless debate and the production of massaged, often meaningless statistics. The immediate assessment exercise may be looked upon as 'window dressing' provision of good clinical care. The results of this survey indicate that our viewpoint seems to be echoed by the patients, the forgotten tribe of their own charter.

We would like to acknowledge the help of the following medical students for their efforts in collecting the information presented in this paper. Ms. J. Chesworth, Mr. S. Harris BSc, Ms. R. Jones BA, Mr. S. Parton BSc, Mr. N. Saw, Mr. A. Wilson BSc.

H.L. CUGNONI, P.J.H. HORMBREY \& S.A.D. MILES

Accident and Emergency Department, St Bartholomew's Hospital, West Smithfield, London

\section{REFERENCE}

1. National Health Service Management Executive (1990) NHS Executive Policy Document, EL92/12.

\section{Gilbert's syndrome during medical residency training}

Gilbert's syndrome is defined as benign, inherited, mild, unconjugated hyperbilirubinemia in the absence of pigment overproduction and with normal routine liver tests. It affects some $2-5 \%$ of the population. Fluctuations in pigment levels are commonly observed, with peak values occurring in association with fasting, strenous exercise, or intercurrent illness. Residency training involves multiple stresses, many of which could be potential causes of rising bilirubin levels in subjects with unrecognized Gilbert's syndrome, as the following cases illustrate.

Three healthy medical residents of the first level presented with scleral jaundice after being on duty in our Emergency Ward's Medicine Section. Extensive evaluation revealed chronic, mild, unconjugated hyperbilirubinemia - not because of haemolysis - and a diagnosis of Gilbert's syndrome was established by exclusion of structural or functional liver disease (Table 1).

A relatively high prevalence of Gilbert's syndrome during medical training was previously reported by Kornberg et al. in a group of healthy medical students. ${ }^{1}$ The potential risk of Gilbert's syndrome during residency training is unknown, but the suspicion that there is an association between work-related stress and peak values of bilirubin levels is raised by the observations presented here. Residency training involves many stressful situations, many of which were not present, or were present to a 